\title{
A Pragmatic Approach to Dynamic Behavior in Electrical Lines Used for Well Intervention Tools
}

Duraij, Martijn Sebastiaan; Xiao, Yudi; Zsurzsan, Gabriel; Zhang, Zhe; Hansen, Mads; Thomsen, Brian Werner

\section{Published in:}

Proceedings of 2020 IEEE International Conference on Industrial Technology

Link to article, DOI:

10.1109/icit45562.2020.9067101

Publication date:

2020

Document Version

Peer reviewed version

Link back to DTU Orbit

Citation (APA):

Duraij, M. S., Xiao, Y., Zsurzsan, G., Zhang, Z., Hansen, M., \& Thomsen, B. W. (2020). A Pragmatic Approach to Dynamic Behavior in Electrical Lines Used for Well Intervention Tools. In Proceedings of 2020 IEEE International Conference on Industrial Technology (pp. 601-606). IEEE.

https://doi.org/10.1109/icit45562.2020.9067101

\section{General rights}

Copyright and moral rights for the publications made accessible in the public portal are retained by the authors and/or other copyright owners and it is a condition of accessing publications that users recognise and abide by the legal requirements associated with these rights.

- Users may download and print one copy of any publication from the public portal for the purpose of private study or research.

- You may not further distribute the material or use it for any profit-making activity or commercial gain

- You may freely distribute the URL identifying the publication in the public portal 


\section{A Pragmatic Approach to Dynamic Behavior in Electrical Lines Used for Well Intervention Tools}

\author{
Martijn Duraij \\ Department of Electrical Engineering \\ Technical University of Denmark \\ Kgs. Lyngby, Denmark \\ msdu@elektro.dtu.dk
}

\author{
Zhe Zhang \\ Department of Electrical Engineering \\ Technical University of Denmark \\ Kgs. Lyngby, Denmark
}

\author{
Yudi Xiao \\ Department of Electrical Engineering \\ Technical University of Denmark \\ Kgs. Lyngby, Denmark
}

\author{
Gabriel Zsurzsan \\ Department of Electrical Engineering \\ Technical University of Denmark \\ Kgs. Lyngby, Denmark
}

\author{
Mads Hansen \\ $D \&$ E Electronics \\ Wellec $A / S$ \\ Allerød, Denmark
}

\author{
Brian Thomsen \\ $D \&$ E Electronics \\ Welltec A/S \\ Allerød, Denmark
}

\begin{abstract}
Electrical lines, also known as wirelines, are commonly used for well intervention techniques to increase flow of oil and gas wells that can be executed during a low service time. Previous studies show the importance of this electrical conductor for power delivery as well as communication purposes. Nevertheless, a validated model and its parameters of this channel are still missing. This papers outlines a geometrical approach to estimate the electrical dynamic behavior for wireline types used in the field with results supported by four different types of validation. The proposed method proves to capture the wireline dynamic behavior characteristics and is particular accurate in modeling the capacitive element within $5 \%$.
\end{abstract}

Index Terms-Electric line, impedance modeling, well intervention, wireline

\section{INTRODUCTION}

The oil and gas industry relies on nimble solutions to boost the performance of the well. These operations, known as well interventions, can consist of tractoring, milling, drilling, cutting and cleaning. A preferred way of performing these tasks is to lower robotic tools into the well environment [1], [2]. By attaching these tools to a cable (Fig. 1), also known as an electric line (e-line) or wireline, the tool can be lowered into the well environment and be pulled out once the job is done. The tool must be powered from surface equipment; hence a fitting estimation of electrical parameters in this wireline is critical to ensure a safe operation.

Well environments are known to be extremely harsh on materials used during well intervention operations. For example, temperatures within the oil and gas well environments can reach up to $200^{\circ} \mathrm{C}$ [3]. Corrosive elements [4] and high pressure may also be present, severely derating the lifetime of the tools and wireline. When oil and gas becomes harder to find and reach, it is expected that more of these harsh conditions will be encountered [5].

The authors would like to thank the Innovation Fund Denmark (IFD) for their financial contribution towards this project under reference number 9065 00005B

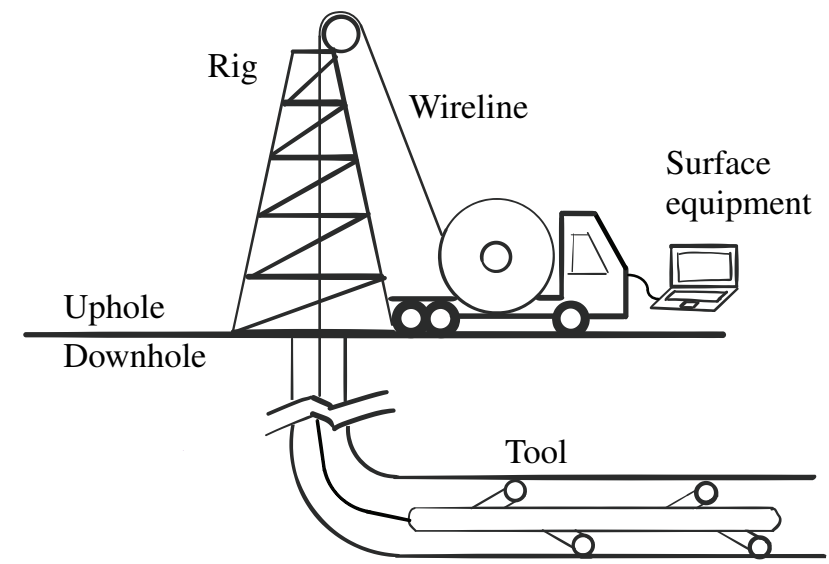

Fig. 1: Example of well intervention with a tractor connected with a wireline to the surface equipment.

The downhole tool is controlled by the surface equipment, which means that a reliable communication channel must be ensured. The wireline is one of possible transmission paths available for this communication [6], [7]. Mono wirelines have two conductive paths in a single cable, which comes in the form of an outer and an inner conductor. Since these cables can be very long, up to $12 \mathrm{~km}$ or more, a large self-inductance can be expected. This inductance is of the foremost importance when high power tools are operating in the well environment. Downhole load steps can cause serious over- or under-voltage faults at the tool-wireline interface during operation. Additionally, the wireline exhibits a length-dependent capacitance, which, paired with the inductance, results in a second order behavior in the transmission path. This limits the available bandwidth for power line communication [8], [9].

Previous studies [7]-[11] concentrate on information transfer rather than the channel construction, parameters and models of transmission paths. Gunarathne et. al. [12] show the power transfer and communication speed limitations of long 
coaxial cables. Tests were performed on a terrestrial RG58 type coaxial cable as it was found to be a suitable substitution for a wireline. No study has yet validated the parameters used in wireline models for typical wirelines used in the field.

The aim of this paper is to determine the dynamic behavior of wirelines, and in this way aid practicing engineers in the well intervention industry. An insight into wireline construction forms a simplified model of a transmission line, after which the electrical parameters can be identified. Using data gathered from various wireline types, measurements are used to validate the chosen model topology, implementation and simulation

\section{WIRELINE PARAMETERS}

Wirelines come in all kinds of variants [13]. This paper focuses on mono-conductor cables, which consist of a core, a dielectric insulator and an armor. In most cases the core of the cable is made of copper, built by a number of strands tightly twisted together and held in place by a dielectric insulator. The outer conductor, i.e. the armor, is normally made from stainless steel such as plough steel. Multiple strands divided into two layers are tightly wound around the core and insulator assembly. Each layer is wound in opposite directions, resulting in a rigid yet flexible wireline.

\section{A. Corrosion resistant electrical lines}

Wirelines can be subjected to high corrosion well environments when exposed to very hostile conditions. Corrosion resistant wirelines are designed to operate under high levels of $\mathrm{H}_{2} \mathrm{~S}$ and $\mathrm{CO}_{2}$ [13], [14]. The armor of these types of wirelines are made of optimized alloys of stainless steel, e.g. 316L. Lower levels of carbon in such alloy increase the ability to withstand corrosive forces. The alloys used for the armor are non-magnetic and therefore have a lower relative permeability than non-corrosion resistive types. The core of corrosion resistant wirelines are often made from nickel plated copper. The application of nickel plating has the advantage of a high corrosion resistance and increased mechanical strength with the drawback of a higher resistivity.

\section{B. Parameter identification}

Two typical mono wireline constructions are depicted in Fig. 2. Both assemblies can be identified as coaxial. The current runs trough the inner conductor, the core, and returns through the armor. Two examples of wirelines, manufactured by Camesa, have a different number of strands and strand diameters $\left(d_{s}\right)$. Around the core are layers of the insulation materials (with relative permittivities $k_{1}$ and $k_{2}$ ). If multiple layers of insulator are used the radius $r_{m}$ marks the interface between the insulators. Outside this structure a total of 30 armor wires are arranged into two layers. The inner armor layer consists of 12 strands wound in clockwise direction around the core assembly; the outer armor has 18 strands wound in the opposite direction. The diameter $\left(d_{a}\right)$ of the armor strands may differ per wireline type and layer.
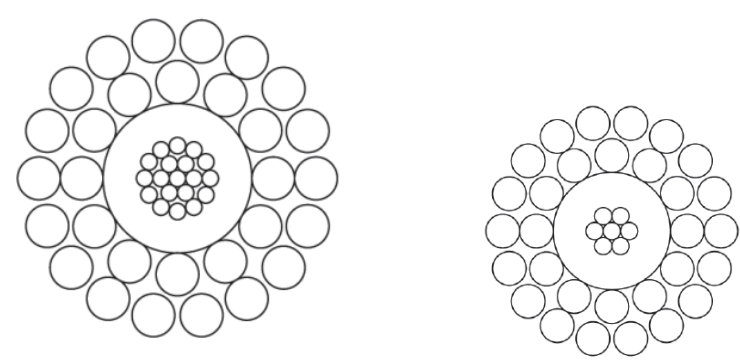

(a) $1 \mathrm{~N} 32$ reprinted from [13].

(b) $1 \mathrm{~N} 22 \mathrm{~S} 75$ reprinted from [13].

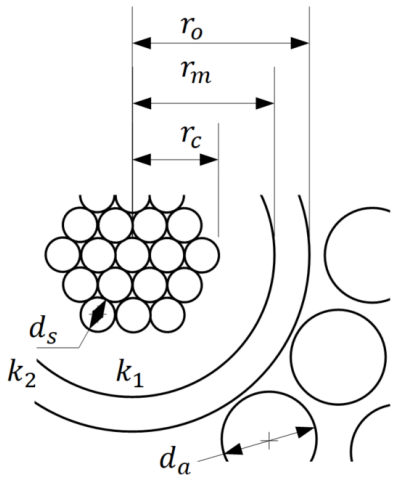

(c) Overview of wireline parameters.

Fig. 2: Examples of typical wireline constructions as used in the field.

The insulator placed between the core and armor conductor allows a voltage to be present between the two conductors. This insulator can be made using various materials such as Ethylene Tetrafluoroethylene (ETFE), Fluorinated Ethylene Propylene (FEP) and other plastic materials. The break down voltage of the insulator varies between $600 \mathrm{~V}$ and $1500 \mathrm{~V}$ and has a given relative permittivity $k_{r}$ between 2 and 2.6 depending on the material. This insulator between the two conductors creates a capacitance that is equally distributed over the full length of the wireline. Wirelines can also be constructed with multiple layers of insulation. These multiple layers each exhibit their own capacitance between the conductors and can therefore be seen as capacitors placed in series.

\section{MethoD}

One of the simplest model implementations for a coaxial cable is a lumped model which is often used for transmission lines in both radio frequency (RF) applications [15] as well for well logging telemetry [16]. This model is a summary of a long chain of parasitic elements in the transmission path, derived as a per length $(\ell)$ unit. These parasitic elements are resistance, inductance and capacitance of the transmission line. When combining all elements to a simplified lumped model one can take the product of the parasitic element per unit length and the actual length of the modeled transmission path. The resistive and inductive element of the wireline are placed in series with the transmission path. The capacitive element of the transmission path is terminated at the receiving end of the wireline. The conduction element $G$ can be ignored to simplify 


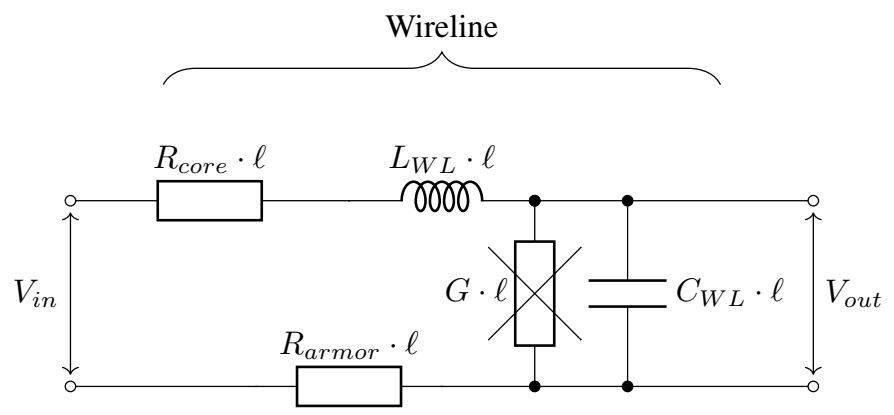

Fig. 3: Lumped RLC model for transmission lines.

the model because it will only have effect at frequencies out of the scope of this research.

\section{A. Model limitations}

At wellsite applications the resistance in the armor is shorted out by winding the total wireline length on a drum, meaning that all outer conductors are shorted together, lowering the impedance seen in the armor. When lowering a tool down in the well environment the armor will be shorted by the metal well casing. This is a metal pipe that runs all the way through the well to isolate the well fluids. This casing has a much better electrical conductivity than the wireline armor. $R_{\text {armor }}$ in the model may therefore be shorted out in some cases to represent field representable measurements.

\section{B. Parameter calculations}

Using a geometrical approach as shown in Fig. 2c, the parameters $\mathrm{R}, \mathrm{L}$ and $\mathrm{C}$ can be identified for use in the lumped RLC model. The resistance in the core and in the armor are given by their respective geometrical areas and their resistivities:

$$
\begin{aligned}
R_{\text {core }} & =\frac{\rho_{C U}}{A_{\text {core }}} \\
R_{\text {armor }} & =\frac{\rho_{C F E}}{A_{\text {armor }}}
\end{aligned}
$$

where $R_{\text {core }}$ is the core resistance per unit length in $\Omega \mathrm{m}^{-1}$, $R_{\text {armor }}$ is the armor resistance per unit length in $\Omega \mathrm{m}^{-1}$, $\rho_{C U}$ is the conductivity of copper in $\Omega \mathrm{m}^{-1}, \rho_{C F E}$ is the conductivity of carbon steel in $\Omega \mathrm{m}^{-1}, A_{\text {core }}$ is the total area of the core conductor in $\mathrm{m}^{2}$ and $A_{\text {armor }}$ is the total area of the armor conductor in $\mathrm{m}^{2}$. The skin-effect of the wire is not addressed in this paper where the bandwidth of interest is up to $200 \mathrm{kHz}$.

The insulator between the core and the armor can be of a singular material or a combination of multiple insulator plastic layers. Various constructions of insulator arrangements and their thickness result in different break-down voltage levels. More important for this study is that they contribute to different levels of parasitic capacitance seen between the core and the armor. The total capacitance is highly depended on the length of the wireline.
TABLE I

\begin{tabular}{|c|c|c|}
\hline Parameter & Description & Value \\
\hline$\rho_{C U}$ & Resistivity of copper & $1.68 \cdot 10^{-8} \Omega \mathrm{m}^{-1}$ \\
\hline$\rho_{C F E}$ & Resistivity of carbon steel & $1.43 \cdot 10^{-7} \Omega \mathrm{m}^{-1}$ \\
\hline$\rho_{316 L}$ & $\begin{array}{l}\text { Resistivity of corrosion re- } \\
\text { sistance } 316 \mathrm{~L} \text { steel }\end{array}$ & $7.4 \cdot 10^{-7} \Omega \mathrm{m}^{-1}$ \\
\hline$\epsilon_{0}$ & Permittivity of free space & $8.854 \cdot 10^{-12} \mathrm{~F} \mathrm{~m}^{-1}$ \\
\hline$k_{F E P}$ & $\begin{array}{l}\text { Relative permittivity of } \\
\text { FEP material }\end{array}$ & 2.0 \\
\hline$k_{E F T E}$ & $\begin{array}{l}\text { Relative permittivity of } \\
\text { EFTE material }\end{array}$ & 2.5 \\
\hline$k_{P F A}$ & $\begin{array}{l}\text { Relative permittivity of } \\
\text { PFA material }\end{array}$ & 2.0 \\
\hline$k_{\text {Poly }}$ & $\begin{array}{l}\text { Relative permittivity of } \\
\text { Poly material }\end{array}$ & 2.25 \\
\hline$\mu_{0}$ & Permeability of free space & $4 \pi \cdot 10^{-7} \mathrm{H} \mathrm{m}^{-1}$ \\
\hline
\end{tabular}

CALCUlation PARAMETERs AT $20^{\circ} \mathrm{C}$

$$
\left(C_{W L}\right)^{-1}=\left(\frac{2 \epsilon_{0} k_{1}}{\ln \left(\frac{r_{m}}{r_{c}}\right)}\right)^{-1}+\left(\frac{2 \epsilon_{0} k_{2}}{\ln \left(\frac{r_{o}}{r_{m}}\right)}\right)^{-1}
$$

The geometrical parameters for $r_{c}, r_{m}$ and $r_{o}$ are depicted in Fig. 2c. $k_{1}$, and when applicable $k_{2}$, is the relative permittivity of the used insulator type. Lastly the self inductance of a coaxial cable in free air can be described as:

$$
L_{W L}=\frac{\mu_{0}}{2 \pi} \ln \left(\frac{r_{o}}{r_{c}}\right)
$$

The model as depicted in Fig.3 can be extended by increasing $\ell[\mathrm{m}]$ but requires significant precision on the identified parameters.

\section{MeAsurements}

A set of 4 different wireline types has been subjected to a series of tests including measurements by LCR meter, step response and frequency sweeps. The cables used all came from Camesa EMC and all have the same geometry as depicted in Fig. 2a, except for the 1N22S75 type which is constructed as depicted in Fig. 2b. All cables have an approximate length of $9 \mathrm{~m}$. The parameters of the measured wireline types are listed in Table II.

TABLE II

WIRELINE PARAMETERS

\begin{tabular}{|l|l|l|l|l|}
\hline & 1N22PTZ & 1N22S75 & 1N32PTZ & 1N32PP \\
\hline Core $[\mathrm{mm}]$ & $19 \times 0.302$ & $7 \times 0.404$ & $19 \times 0.361$ & $19 \times 0.361$ \\
\hline Armor $[\mathrm{mm}]$ & 0.787 & 0.787 & 1.103 & 1.103 \\
\hline \multirow{2}{*}{ Insulator } & FEP + & PFA & $\begin{array}{l}\text { EP } \\
\text { ETFE }\end{array}$ & Poly \\
\hline
\end{tabular}

There are two wireline diameters, namely $5.69 \mathrm{~mm}$ for the $1 \mathrm{~N} 22$ types and $8.18 \mathrm{~mm}$ for the $1 \mathrm{~N} 32$ types. The total diameter affects the geometry and therefore the extracted parameters 
used to model the core, insulation layer and armor. The PTZ wirelines have a double insulator which is a combination of FEP and ETFE material. The S75 wireline is a corrosion resistant type which uses a PFA (Perfluoroalkoxy) insulator type. The 1N32PP wireline has an insulator of Poly material (Propylene Copolymer) and is not corrosion resistant.

TABLE III

Calculated Wireline Parameters at $\ell=9 \mathrm{~m}$

\begin{tabular}{|l|l|l|l|l|}
\hline & 1N22PTZ & 1N22S75 & 1N32PTZ & 1N32PP \\
\hline$R_{\text {core }}[\Omega]$ & 0.1111 & 0.1685 & 0.0777 & 0.0777 \\
\hline$R_{\text {armor }}[\Omega]$ & 0.6614 & 0.4564 & 0.0428 & 0.0428 \\
\hline$L_{W L}[\mu \mathrm{H}]$ & 1.0877 & 1.4986 & 1.4057 & 1.4057 \\
\hline$C_{W L}[\mathrm{nF}]$ & 1.8519 & 1.2027 & 1.4425 & 1.4443 \\
\hline
\end{tabular}

From Table III it can be seen that the calculated parameters for the $1 \mathrm{~N} 32 \mathrm{PTZ}$ and $1 \mathrm{~N} 32 \mathrm{PP}$ wireline types are very close, therefore their modeled dynamic behavior is expected to be the same.

\section{A. LCR meter measurements}

Measuring the inductive behavior of the wireline $\left(L_{W L}\right)$ requires that the end of the wireline is terminated in a short circuit. When measuring the capacitive behavior $\left(C_{W L}\right)$, the end is left open. DC measurements of $R_{\text {core }}$ and $R_{\text {armor }}$ are performed using a four point measurement method. With a simple hand-held LCR meter, results where found as displayed in Table IV.

TABLE IV

LCR MEASUREMENT RESUlts

\begin{tabular}{|l|l|l|l|l|}
\hline & 1N22PTZ & 1N22S75 & 1N32PTZ & 1N32PP \\
\hline$R_{\text {core }}[\Omega]$ & 0.146 & 0.225 & 0.124 & 0.115 \\
\hline$R_{\text {armor }}[\Omega]$ & 0.733 & 1.129 & 0.622 & 0.574 \\
\hline$L_{W L}[\mu \mathrm{H}]$ & 10 & 3 & 3 & 11 \\
\hline$C_{W L}[\mathrm{nF}]$ & 1.76 & 1.20 & 1.41 & 1.48 \\
\hline
\end{tabular}

Coupling the results from Table IV back to the calculated parameters in Table III the resistance calculations for the core are 30 to $60 \%$ off. This large deviation can be accepted when measuring very low resistances. The approach to estimate the capacitance in the wireline fits the measured results within $5 \%$ error. The measured armor resistance is much higher than calculated which can also be due to measurement error. The inductance does not match the estimated values from Section III-B. The used calculation method does not account for a large difference in material permeability between the core conductor and the armor conductor.

\section{B. Frequency sweep}

The measurement setup from the LCR measurements can be extended to verify the impedance of the wireline as a function of frequency. The requirements for termination impedance remain the same for measuring the inductance and capacitance. 9m wireline impedance in short circuit

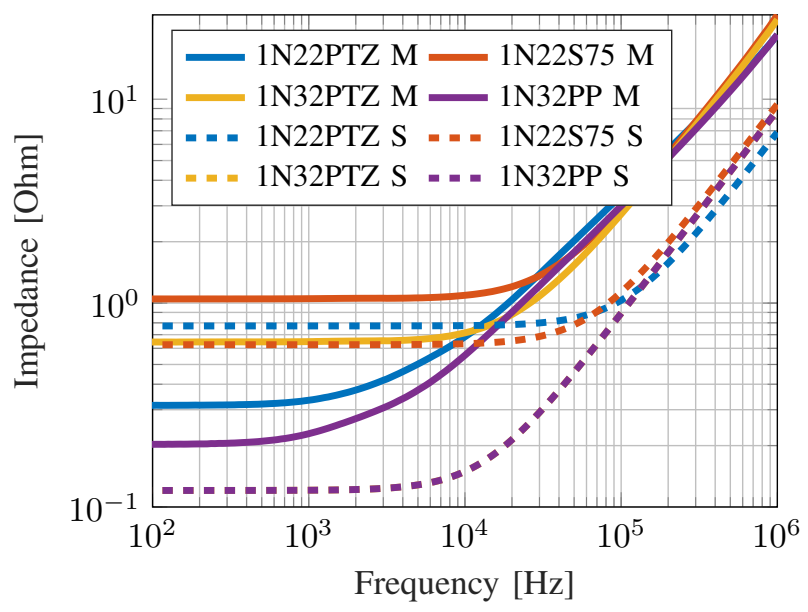

Fig. 4: Frequency response of the impedance measurement by current injection of the $9 \mathrm{~m}$ wireline types used to verify the inductive behavior.

\section{9m wireline impedance in open circuit}

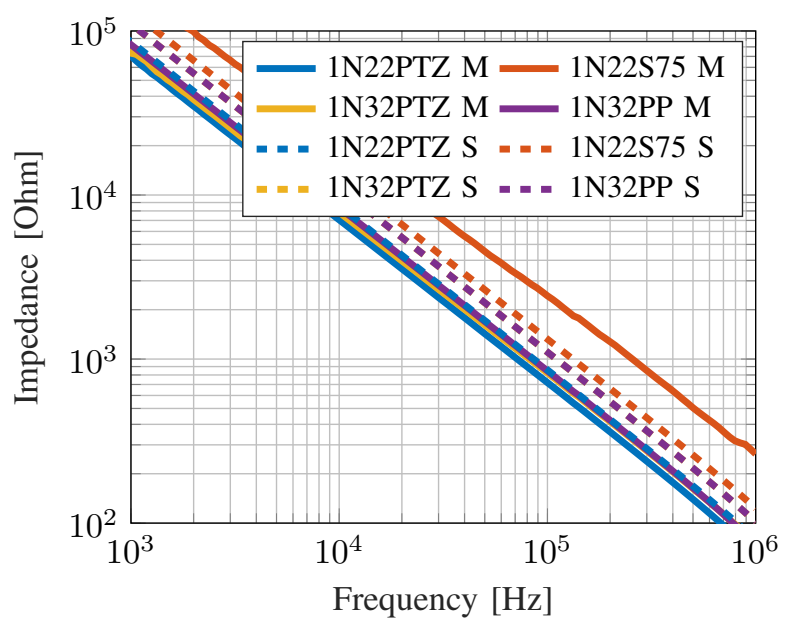

Fig. 5: Frequency response of the impedance measurement by current injection of the $9 \mathrm{~m}$ wireline types used to verify the capacitive behavior.

An Omicron Bode100 analyzer was used with an injection transformer to inject a current into the wireline. The results can then be compared to the models generated from the calculated parameters. The expected impedance can be described as in (5) where $R_{D C}$ is the sum of $R_{\text {core }}$ and $R_{\text {armor }}$.

$$
Z_{W L}(j \omega)= \begin{cases}R_{D C}+j \omega L_{W L}, & \text { short circuit } \\ R_{D C}+j \omega L_{W L}+\frac{1}{j \omega C_{W L}}, & \text { open circuit }\end{cases}
$$

It can be observed from Fig. 4 and Fig. 5 that the suggested model (simulated responses denoted with $\mathrm{S}$ ) captures the dynamic characteristics of the measured (measurements denoted with M) wireline. However, it should be noted that the modeled inductive element is again the most uncertain 
parameter. Using the measurements and (5) the electrical parameters are extracted and presented in Table $\mathrm{V}$.

TABLE V

FREQUENCY RESPONSE EXTRACTED PARAMETERS

\begin{tabular}{|l|l|l|l|l|}
\hline & 1N22PTZ & 1N22S75 & 1N32PTZ & 1N32PP \\
\hline$R_{D C}[\Omega]$ & 0.315 & 1.048 & 0.644 & 0.203 \\
\hline$L_{W L} @ 50 \mathrm{kHz}[\mu \mathrm{H}]$ & 5.68 & 4.28 & 4.25 & 5.12 \\
\hline$C_{W L} @ 50 \mathrm{kHz}[\mathrm{nF}]$ & 2.23 & 0.70 & 1.97 & 1.88 \\
\hline
\end{tabular}

\section{Step response}

As the inductance of the wireline shows the largest deviation, a third measurement was conducted using a step response. When applying a step response to a first order LR circuit the inductance can be validated using the measured time constant. This was performed on a short piece of wireline with a small inductance. Step timing becomes critical wherefore a NF Corporation HSA4101 high speed bipolar amplifier was used. Due to the expected low values of resistance and inductance, the output impedance of this amplifier had to be taken into account. This is the reason for the small settling time in the displayed waveforms. The amplifier has a verified output resistance of $1.5 \Omega$ in parallel with an inductance of $0.5 \mu \mathrm{H}$. The load of the wireline measurement setup was $1.1 \Omega$ where the excitation frequency was kept at $1 \mathrm{~Hz}$. The selfinductance was estimated using the measured time constant of the measured output signal $\tau_{\text {out }}$ and dc resistance with the results displayed in Table VI.

$$
\begin{gathered}
L_{W L}=\tau_{\text {out }} \cdot\left(R_{\text {load }}+R_{\text {core }}+R_{\text {armor }}\right) \\
\text { TABLE VI } \\
\text { STEP RESPONSE EXTRACTED PARAMETERS }
\end{gathered}
$$

\begin{tabular}{|l|l|l|l|l|}
\hline & 1N22PTZ & 1N22S75 & 1N32PTZ & 1N32PP \\
\hline$R_{D C}[\Omega]$ & 0.88 & 1.89 & 0.75 & 0.69 \\
\hline$L_{W L}[\mu \mathrm{H}]$ & 10.52 & 6.33 & 6.36 & 9.18 \\
\hline
\end{tabular}

\section{Long length validation}

When extending the model to a used-case representable length, a propagation delay is expected. Electric energy in a conductor travels close to the speed of light, but is limited by the permittivity of the insulator in the closed current loop. In the wireline this insulator is placed between the core and the armor. The velocity of electrical energy, $v_{e}\left[\mathrm{~m} \mathrm{~s}^{-1}\right]$, is therefore a fraction of the speed of light, $c\left[\mathrm{~ms}^{-1}\right]$, with a factor of the square root of the relative permittivity of the insulator, $k=k_{1}+k_{2}$.

$$
v_{e}=\frac{c}{\sqrt{k}}
$$

For a long piece of wire, this adds up to a time difference that can be measured as a propagation delay trough the
1N32PP 9m wireline step response

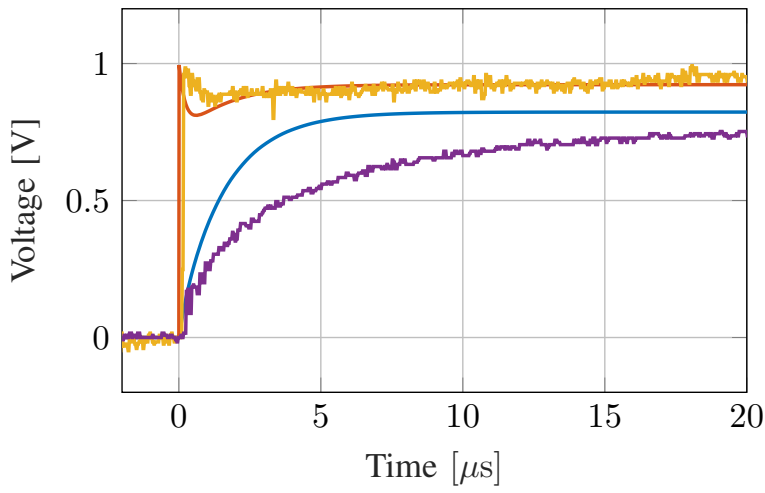

1N32PTZ 9m wireline step response

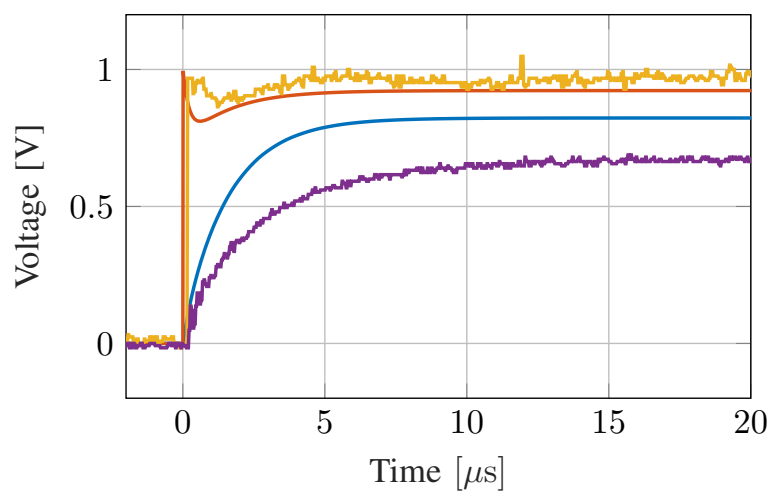

1N22S75 9m wireline step response

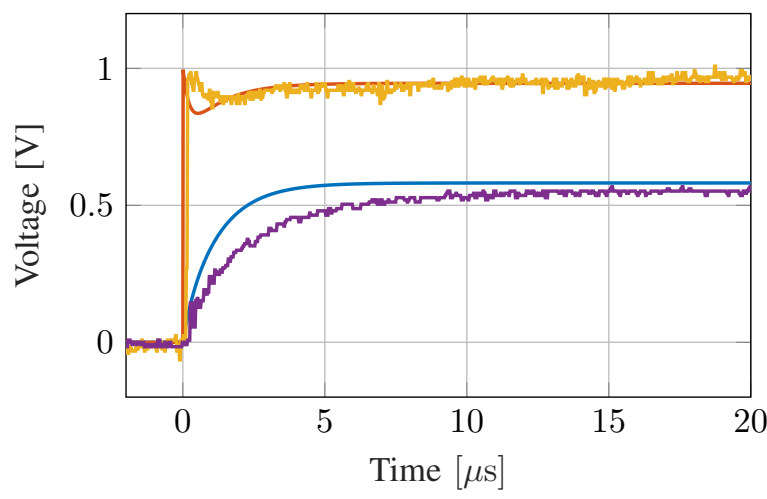

1N22PTZ 9m wireline step response

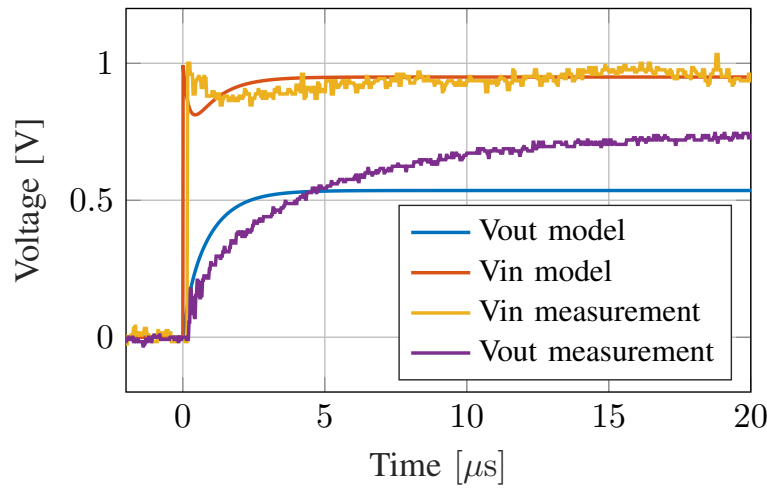

Fig. 6: Step response on $9 \mathrm{~m}$ wirelines. 

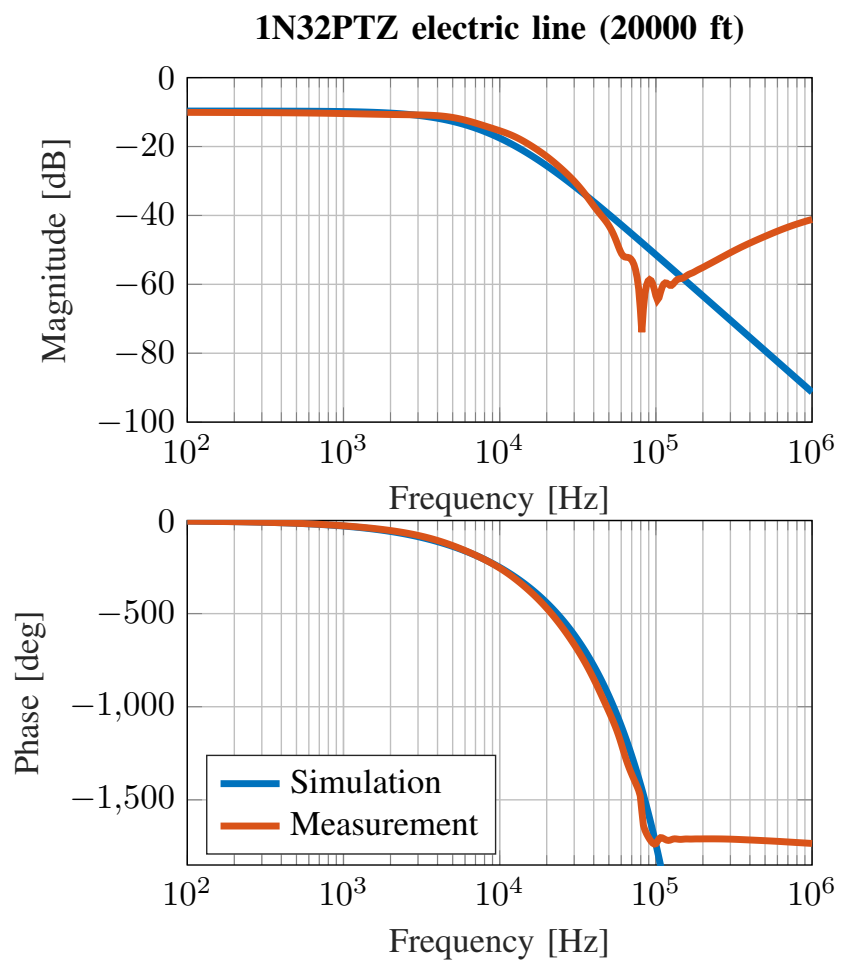

Fig. 7: Gain and phase response measurements of the $6096 \mathrm{~m}(20000$ ft.) $1 \mathrm{~N} 32 \mathrm{PTZ}$ wireline compared with the simulation.

wireline. This leads to a linear phase-shift adding to the model for long wirelines.

$$
t_{d}=\frac{\ell}{v_{e}}
$$

A transfer function from the wireline, $H_{W L}$, therefore has to be extended with a delay element, $t_{d}$. The system transfer function, $H_{\text {sys }}$, can then be written in the s-domain.

$$
H_{\text {sys }}(s)=H_{W L}(s) \cdot e^{-t_{d} s}
$$

This theory was tested with a $6096 \mathrm{~m}(20000 \mathrm{ft}$.) 1N32PTZ wireline. Since all the armor conductors are shorted out on the drum, the effect of the armor impedance is neglected in the transfer function calculation. The response was verified with a Bode100 analyzer with a source impedance of $Z_{\text {out }}=50 \Omega$ and a load impedance $Z_{\text {load }}=50 \Omega$. The propagation delay $t_{d}=43.61 \mu \mathrm{s}$.

The measurements show that the extracted parameters from the geometrical construction can be used to generate a model for long wirelines. The measured attenuation follows the same trend as the simulated response where the measured and simulated phase shift responses overlap each other. Above $90 \mathrm{kHz}$ the measurement setup is unable to provide accurate data. Due to the the large attenuation in the wireline and delay introduced linear phase shift, no valid measurements can be obtained above this frequency using the Bode 100 measurement setup.

\section{CONClusion}

From a construction viewpoint, the electrical parameters of a wireline were identified using geometry and material parameters. A lumped model RLC circuit was defined which has been verified for short lengths using dc measurements, frequency responses and step responses. The results show that the lumped model is indeed an accurate approximation of the dynamic behavior of the electric line. This developed model can be used for power electronics and communications development for intervention tools in the oil and gas industry. It has also been found that the model is representable for an field used length of $6096 \mathrm{~m}$.

To make the model more precise, additional work is required in defining the armor, on a single strand as well as on a drum. Variations in alloy parameters can be taken into account for corrosion resistant wireline types. Finally, temperature effects can be studied as they will be present in the actual harsh environment conditions seen in oil and gas wells.

\section{REFERENCES}

[1] J. Hallundboek, K. Ostvang, J. Haukvik, and T. Skeie, "Wireline Well Tractor: Case histories," in Proceedings of the Annual Offshore Technology Conference, vol. 4, 1997, pp. 1-4.

[2] D. Denney, "Wireline Well Tractor," Journal of Petroleum Technology, vol. 50, no. 06, pp. 51-52, 2015.

[3] J. J. Den Boer, "The use of high temperature electronics in downhole applications," HITEN 1999 - 3rd European Conference on High Temperature Electronics, pp. 149-152, 1999.

[4] G. A. Vaughn and H. E. Chaung, "Wireline Materials for Sour Service," Materials Performance, vol. 21, no. 1, pp. 44-50, 1982. [Online]. Available: https://findit.dtu.dk/en/catalog/2367474922 http://www.scopus.com/inward/record.url?eid=2-s2.0$0019910450 \&$ partnerID=40\&md5=fce27133c85bbe8a1c1bd8fda6900d 94

[5] Equinor ASA, "Energy Perspectives 2018: Long term macro and market outlook," 2018. [Online]. Available: https://www.equinor.com/en/whatwe-do/exploration.html

[6] D. Cao, “Oil-field services' data acquisition system - A globally distributed development," Proceedings - International Computer Software and Applications Conference, no. July, p. 5, 2008.

[7] X. Liang and W. Xu, "Downhole monitoring tool design using power line disturbances," 2015 IEEE/IAS 51st Industrial and Commercial Power Systems Technical Conference, I and CPS 2015, pp. 1-11, 2015.

[8] W. Zhang, Y. Shi, and J. Tang, "Application of an improved ADSL technique in the high-speed wireline logging telemetry system," 2007 8th International Conference on Electronic Measurement and Instruments, ICEMI, pp. 2108-2112, 2007.

[9] A. Cashion and C. Grzegorz, "High Temperature Quadrature Amplitude Modulation over Orthogonal Frequency Division Multiplexing," 2018.

[10] Z. Wang, D. J. Liu, Q. H. Ai, X. Cheng, D. H. Xue, A. D. Yang, and Y. G. Zhao, "A frequency domain scheme for high speed telemetry down hole wire line communication," Proceedings - 5th International Conference on Instrumentation and Measurement, Computer, Communication, and Control, IMCCC 2015, pp. 1413-1417, 2016.

[11] Y. Qureshi, "Dynamic impedance matching of transmission cables for downhole tools," pp. 12-12, 2006.

[12] G. Gunarathne, E. Christidis, Y. Qureshi, A. Miller, and N. Deans, "Analysis and optimisation of transmission characteristics of cables for down-hole tools and data acquisition systems," pp. 86-91, 2003.

[13] CamesaEMC, "Electro-Mechanical Cables," 2019.

[14] "New wireline steel grade," Wire, vol. 55, no. 4, pp. 36-37, 2005. [Online]. Available: https://findit.dtu.dk/en/catalog/252373727

[15] The American Relay League, "Chapter 20: Transmission Lines," The ARRL Handbook for Radio Communications, 2010. [Online]. Available: http://www.eas.uccs.edu/ mwickert/ece3110/lecture_notes/N3110_2.pdf

[16] L. Xu, J. Chen, Z. Cao, X. Liu, and J. Hu, "Manchester code telemetry system for well logging using quasi-parallel inductive-capacitive resonance," Review of Scientific Instruments, vol. 85, no. 7, 2014. [Online]. Available: http://dx.doi.org/10.1063/1.4889888 